\title{
Unimodality and Multimodality Cryodebridement for Airway Obstruction. A Single-Center Experience with Safety and Efficacy
}

\section{Citation}

Inaty, Hanine, Erik Folch, Robert Berger, Sebastian Fernandez-Bussy, Sumit Chatterji, Daniel Alape, and Adnan Majid. 2016. "Unimodality and Multimodality Cryodebridement for Airway Obstruction. A Single-Center Experience with Safety and Efficacy." Annals of the American Thoracic Society 13 (6) (June): 856-861. doi:10.1513/annalsats.201508-486oc.

\section{Published Version}

10.1513/annalsats.201508-486oc

\section{Permanent link}

http://nrs.harvard.edu/urn-3:HUL.InstRepos:37047506

\section{Terms of Use}

This article was downloaded from Harvard University's DASH repository, and is made available under the terms and conditions applicable to Other Posted Material, as set forth at http:// nrs.harvard.edu/urn-3:HUL.InstRepos:dash.current.terms-of-use\#LAA

\section{Share Your Story}

The Harvard community has made this article openly available.

Please share how this access benefits you. Submit a story. 


\title{
Unimodality and Multimodality Cryodebridement for Airway Obstruction \\ A Single-Center Experience with Safety and Efficacy
}

\author{
Hanine Inaty ${ }^{1,2}$, Erik Folch ${ }^{1}$, Robert Berger ${ }^{1}$, Sebastian Fernandez-Bussy ${ }^{3}$, Sumit Chatterji ${ }^{4}$, Daniel Alape ${ }^{1}$, and \\ Adnan Majid ${ }^{1}$ \\ ${ }^{1}$ Division of Thoracic Surgery and Interventional Pulmonology, Beth Israel Deaconess Medical Center, Harvard Medical School, Boston, \\ Massachusetts; ${ }^{2}$ Department of Pulmonary and Critical Care Medicine, Cleveland Clinic Foundation, Cleveland, Ohio; ${ }^{3}$ División de \\ Cirugía Toráxica y Neumología Intervencional, Clinica Alemana, Universidad Del Desarrollo, Santiago, Chile; and ${ }^{4}$ Department of \\ Respiratory Medicine, Cambridge University Hospitals NHS Trust, Cambridge, United Kingdom
}

\section{Abstract}

Rationale: Cryodebridement (CD) refers to the removal of obstructive material from the lumen of the tracheobronchial tree by freezing with a cryoprobe, which is usually inserted through a flexible bronchoscope. This method of achieving instant recanalization of airways has been established for over 20 years, but published experience comprises limited case series.

Objectives: This study describes a single large-volume referral center experience, including clinical outcomes and safety profile.

Methods: Electronic medical records of 156 patients who underwent bronchoscopic CD between December 2007 and March 2012 as the primary method to relieve airway obstruction were reviewed retrospectively.

Measurements and Main Results: The most frequent cause of airway obstruction was malignancy $(n=88)$, with non-small-cell lung cancer and metastatic renal cell carcinoma being the most common etiologies. The site of obstruction was localized to the central airways in 63 patients $(40 \%)$ and the distal airways in 44 patients (28\%), and it was diffuse in 49 patients (32\%). Bronchoscopic airway patency was achieved in $95 \%$ of patients, with the highest success rates found in those with obstruction localized in the central airways. Improvement in symptoms occurred in 118 (82\%) of 144 symptomatic patients. Serious complications were reported in 17 patients (11\%) and included respiratory distress, severe bleeding, airway injury, and hemodynamic instability. All patients responded to treatment, and no intra- or postoperative deaths were reported.

Conclusions: CD, when used alone or in combination with other endoscopic treatment modalities, appears to be safe and effective in treating endoluminal airway obstruction.

Keywords: airway obstruction; bronchoscopy; cryodebridement

(Received in original form August 4, 2015; accepted in final form January 22, 2016)

Supported in part by the Thoracic Foundation (Overholt) (Boston, MA).

Author Contributions: Initial concept: A.M., H.I., and E.F.; data collection: H.I.; initial manuscript drafting: H.I.; analysis: H.I. and D.A.; and manuscript editing and revisions: A.M., H.I., R.B., E.F., S.C., and S.F.-B.

Correspondence and requests for reprints should be addressed to Adnan Majid, M.D., Division of Thoracic Surgery and Interventional Pulmonology, Beth Israel Deaconess Medical Center, Harvard Medical School, 185 Pilgrim Road, Deaconess 201, Boston, MA 02215. E-mail: amajid@bidmc.harvard.edu

Ann Am Thorac Soc Vol 13, No 6, pp 856-861, Jun 2016

Copyright $\odot 2016$ by the American Thoracic Society

DOI: 10.1513/AnnalsATS.201508-4860C

Internet address: www.atsjournals.org

Airway obstruction is usually associated with respiratory symptoms and carries significant morbidity and mortality.

Common causes are primary and metastatic cancers, benign tumors, inflammatory airway strictures, and foreign bodies (1). Symptoms include dyspnea, cough, wheeze, stridor, and hemoptysis. Some patients with distal (lobar or segmental) obstruction may not be symptomatic but are at risk for postobstructive complications such as pneumonia or pulmonary abscess and should be considered for endobronchial recanalization. Critical obstruction of the central airways is a medical emergency, and emergent treatment is required in patients with severe respiratory distress.

Cryotherapy is one of several endoscopic modalities available for recanalization of obstructed airways. The technique is performed by deployment of a cryoprobe through the working channel of a fiberoptic bronchoscope. The cryoprobe 
is cooled to $-89^{\circ} \mathrm{C}$ by sudden expansion of an inert gas such as nitrous oxide in an insulated circuit according to the JouleThomson effect. Contact with the cold tip freezes the tissue and facilitates its removal (1-3).

More recently, with improved cryoprobe resilience, cryodebridement (CD) techniques (also called cryosurgery) have been developed to achieve immediate recanalization, reducing the need for repeat endoscopic procedures (1). However, experience with this technique has been limited (3-7), and the aim of this study was to contribute to the knowledge of $\mathrm{CD}$ in this context.

\section{Methods}

After the study was approved by the Beth Israel Deaconess Medical Center Institutional Review Board (IRB 2013-P000161), we reviewed the electronic medical records of all patients who were treated with $\mathrm{CD}$ as the primary endoscopic method for relieving airway obstruction between December 2007 and March 2012 at the Beth Israel Deaconess Medical Center.

Both malignant and benign etiologies were included in this study. Patients who were treated with additional modalities such as mechanical debridement with forceps and/or electrosurgical techniques (argon plasma coagulation [APC] or electrocautery) as a complementary method were also included. Airway diameter estimated to be less than $50 \%$ was defined as a clinically significant obstruction (2).

The narrowing was classified as central when located in the trachea, main stem bronchi, or bronchus intermedius; distal when limited to the lobar and/or segmental bronchi; and diffuse when both central and distal airways were involved. Airway lesions were classified as endobronchial, extrinsic, or mixed (2). The patient's location at the time of presentation was noted.

All procedures were performed in the operating room with the patient under total intravenous anesthesia (propofol, fentanyl, and paralytics). Patients were intubated with the aid of a rigid bronchoscope (Bryan-Dumon; Bryan Corporation, Woburn, MA), and jet ventilation was provided with a Monsoon III high-frequency ventilator (ACUTRONIC Medical Systems, Hirzel, Switzerland). A therapeutic flexible bronchoscope
(OLYMPUS XT-160; Olympus America, Center Valley, PA) was introduced through the rigid barrel, and the airways were inspected down to subsegmental levels.

As per our protocol, the CD technique was used as the primary method for mechanical debridement of obstructive endobronchial lesions located in the trachea, main stem bronchi, bronchus intermedius, and lobar bronchi. For lesions located at the segmental and subsegmental levels, the flexible forceps was used as the main tool. The cryoprobe, owing to its size, adheres to normal mucosa when used in the small distal airways, causing bleeding upon extraction of the target lesion. In addition, for patients undergoing photodynamic therapy, CD was used to remove necrotic tumor debris 48 to 72 hours after activation.

After the target lesion was identified, the tip of the flexible bronchoscope was advanced within $1 \mathrm{~cm}$ proximal to the obstructive lesion. A 2.4-mm flexible cryoprobe (ERBOKRYO CA; ERBE Elektromedizin $\mathrm{GmbH}$, Tübingen, Germany) was introduced through the working channel of the flexible bronchoscope, and the tip was placed in direct contact with the obstructive tissue whenever possible by penetrating the substance of the target tissue to achieve maximal circumferential contact for freezing. Nitrous oxide delivered through the cryoprobe cooled the tip for 5-15 seconds to $-89^{\circ} \mathrm{C}$. The freezing time used was dependent on the size of the lesion and the freezing effect visualized during the procedure. Next, the flexible bronchoscope, along with the cryoprobe and adherent frozen tissue, was withdrawn en bloc. The tip was then thawed in a warm-water bath at $37.5^{\circ} \mathrm{C}$ to facilitate separation of the tissue from the probe.
The use of a rigid bronchoscope facilitated multiple applications until complete or near-complete recanalization was achieved while providing adequate oxygenation, ventilation, and lung isolation (Figures 1A and 1B). Electrosurgical techniques such as electrocautery and APC were used for hemostasis after debridement. The use of the latter was limited to the central airways, owing to concern for air embolism as a potential complication. When mixed lesions were treated, cryorecanalization was often accompanied by balloon dilation and at times by stent placement.

Complete restoration of airway patency was viewed as successful if no residual stenosis was visualized bronchoscopically. It was viewed as partially successful if residual stenosis was noted but the therapeutic flexible bronchoscope with an outer diameter of $6.2 \mathrm{~mm}$ could be passed through the obstruction and distal airways could be visualized. It was considered not successful if the therapeutic flexible bronchoscope could not traverse the stenotic segment (5). Chest computed tomographic (CT) scans were reviewed up to 8 weeks postintervention. The purpose of obtaining the imaging studies was to monitor progression or regression of the disease, verify stent position, and establish lung reexpansion. Radiologic improvement was defined by the treating physician (A.M. or E.F.) as increase in airway diameter and expansion of the lung.

Major complications were defined as respiratory failure leading to endotracheal intubation (ETI) or noninvasive ventilation (NIV), severe bleeding, pneumothorax, hemodynamic instability, airway perforation, and death during or within 30 days of the procedure. Complications
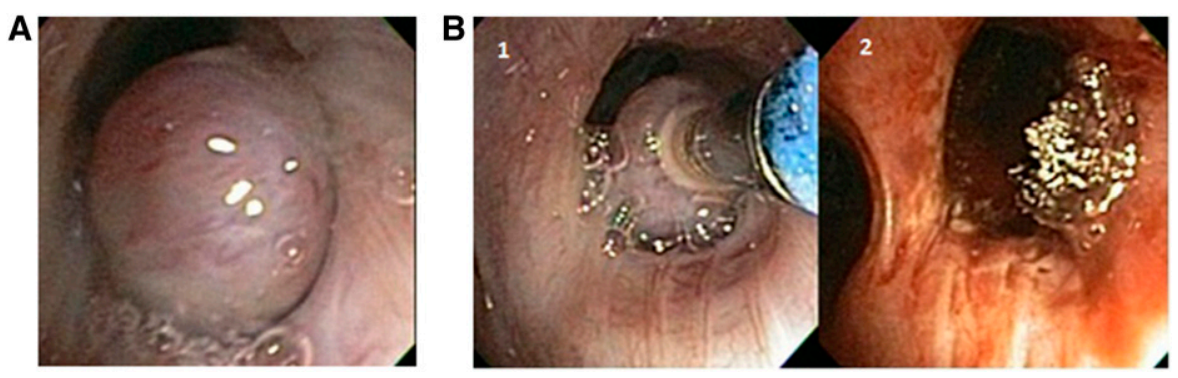

Figure 1. (A) Left lower lobe bronchial obstruction due to metastatic renal cell carcinoma. $(B, 1)$ Cryodebridement using a $2.4-\mathrm{mm}$ flexible cryoprobe. $(B, 2)$ Electrocautery was applied to the base of the tumor after mechanical debridement, with complete airway patency during the same endoscopic procedure. 
Table 1. Bronchoscopic and symptomatic responses to cryodebridement according to location and type of tumor

\begin{tabular}{|c|c|c|c|c|c|}
\hline & \multirow[t]{2}{*}{ Cases Treated (n [\%]) } & \multicolumn{3}{|c|}{ Patency } & \multirow{2}{*}{$\begin{array}{l}\text { Symptoms Improved } \\
\text { (n [\%]) }\end{array}$} \\
\hline & & Complete ( $\boldsymbol{n}[\%])$ & Partial (n [\%]) & None ( $n[\%])$ & \\
\hline \multicolumn{6}{|l|}{ Location } \\
\hline Central & $63(40 \%)$ & $52(83 \%)$ & $10(16 \%)$ & $1(0.6 \%)$ & 49 (89\%) \\
\hline Distal & $44(28 \%)$ & $24(55 \%)$ & $16(36 \%)$ & $4(9 \%)$ & $33(87 \%)$ \\
\hline Diffuse & 49 (32\%) & 19 (39\%) & $27(55 \%)$ & $3(6 \%)$ & $36(84 \%)$ \\
\hline \multicolumn{6}{|l|}{ Lesion type } \\
\hline Endobronchial & $66(42 \%)$ & $56(85 \%)$ & $5(7.5 \%)$ & $5(7.5 \%)$ & 56 (93\%) \\
\hline Extrinsic & $0(0 \%)$ & $0(0 \%)$ & $0(0 \%)$ & $0(0 \%)$ & $0(0 \%)$ \\
\hline Mixed & $90(58 \%)$ & $39(43 \%)$ & $48(53 \%)$ & $3(4 \%)$ & $62(65.7 \%)$ \\
\hline
\end{tabular}

*The percentage was calculated out of the total number of patients who were symptomatic upon presentation and for whom information regarding their symptoms post-cryodebridement was available in their records.

were considered clinically significant if the patient's condition after CD warranted a step-up in the level of clinical care (i.e., hospitalization or intensive care unit admission). Bleeding was graded as mild if controlled by application of cold saline and/or epinephrine solution; moderate if controlled by APC or electrocautery; and severe if there was a need for transfusion of blood products, endobronchial blockade, bronchial artery embolization, or endotracheal intubation for suctioning of blood.

\section{Results}

Between December 2007 and March 2012, 156 patients underwent $\mathrm{CD}$ with a flexible cryoprobe for relief of airway obstruction at our institution. The male-to-female ratio was $1: 1$. The patients' mean age was 63 years (range, 21-88 yr). Most patients were symptomatic at presentation $(\mathrm{n}=144$ [92\%]). Dyspnea, cough, and hemoptysis were the most common symptoms; these were noted in 87 (56\%), 58 (37\%), and $23(26 \%)$ of patients, respectively. Most patients had multiple symptoms at presentation. Because of severe symptoms, 31 patients $(20 \%)$ were initially admitted to the intensive care unit. Location of the obstruction was central in 63 patients (40\%), distal in 44 patients $(28 \%)$, and diffuse in 49 patients (33\%). The lesions were endobronchial in 66 patients $(42 \%)$ and mixed in 90 patients (58\%) (Table 1).

The most frequent causes of malignant airway obstruction were non-small-cell lung cancer and renal cell carcinoma in 49 patients (31\%) and 19 patients (12\%), respectively (Table 2 ). The most common cause of benign airway obstruction was granulation tissue in 40 patients (26\%) (Table 3). Of those with malignant obstruction, complete or partial airway patency was achieved in $38(43 \%)$ and 45 (51\%) of 88 patients, respectively, after the first procedure. For those with benign airway obstruction, complete or partial airway patency was accomplished in 56 $(82 \%)$ and $9(13 \%)$ of 68 patients, respectively.

Because of partial or no symptomatic response, a second bronchoscopy was performed within 4 weeks of the first procedure in 35 patients $(22 \%)$, in 19 of whom it was done for malignant airway obstruction. Partial to complete patency was achieved in 32 (91\%), and no improvement was achieved in 3 patients (8.5\%); however, 2 of these latter patients had a third procedure within 4 weeks with

Table 2. Bronchoscopic and symptomatic responses to cryodebridement according to etiology

\begin{tabular}{|c|c|c|c|c|c|}
\hline & \multirow{2}{*}{$\begin{array}{c}\text { Cases } \\
\text { Treated (n [\%]) }\end{array}$} & \multicolumn{3}{|c|}{ Patency } & \multirow{2}{*}{$\begin{array}{c}\text { Symptoms Improved } \\
\text { (n [\%]) }\end{array}$} \\
\hline & & Complete ( $n$ [\%]) & Partial (n [\%]) & None (n [\%]) & \\
\hline \multicolumn{6}{|l|}{ Benign } \\
\hline Foreign body & $5(3 \%)$ & $5(100 \%)$ & $0(0 \%)$ & $0(0 \%)$ & 5 (100\%) \\
\hline Blood clot & $11(7 \%)$ & $11(100 \%)$ & $0(0 \%)$ & $0(0 \%)$ & $11(100 \%)$ \\
\hline Mucus plug & $1(0.6 \%)$ & $1(100 \%)$ & $0(0 \%)$ & $0(0 \%)$ & $1(100 \%)$ \\
\hline Fungal cast & $3(2 \%)$ & $3(100 \%)$ & $0(0 \%)$ & $0(0 \%)$ & $3(100 \%)$ \\
\hline Granulation tissue & $40(26 \%)$ & $31(78 \%)$ & $9(22 \%)$ & $0(0 \%)$ & $28(85 \%)$ \\
\hline Benign tumors & $6(4 \%)$ & $6(100 \%)$ & $0(0 \%)$ & $0(0 \%)$ & $6(100 \%)$ \\
\hline Pseudomembrane & $1(0.6 \%)$ & $1(100 \%)$ & $0(0 \%)$ & $0(0 \%)$ & $0(100 \%)$ \\
\hline \multicolumn{6}{|l|}{ Malignant } \\
\hline Primary adenocarcinoma & $12(8 \%)$ & $5(42 \%)$ & $7(58 \%)$ & $0(0 \%)$ & $9(90 \%)$ \\
\hline Squamous cell lung cancer & $31(20 \%)$ & $13(42 \%)$ & $16(52 \%)$ & $2(6 \%)$ & $22(81 \%)$ \\
\hline Large cell lung cancer & $3(2 \%)$ & $1(33 \%)$ & 2 (69\%) & $0(0 \%)$ & $2(100 \%)$ \\
\hline Small cell lung cancer & $3(2 \%)$ & $0(0 \%)$ & $3(100 \%)$ & $0(0 \%)$ & $3(100 \%)$ \\
\hline Renal cell cancer & $19(12 \%)$ & $7(37 \%)$ & $11(58 \%)$ & $1(5 \%)$ & $15(88 \%)$ \\
\hline Other & 20 (14\%) & 12 (60\%) & $6(30 \%)$ & $2(10 \%)$ & 13 (76\%) \\
\hline
\end{tabular}


Table 3. Underlying etiology of granulation tissues

\section{Etiology of Granulation Tissue}

Stents

Tracheostomy/T-tube/transtracheal oxygen catheter

Other (idiopathic, foreign body, granulomatosis with polyangiitis)

Total number

\section{Number (\%)}

$17(42.5 \%)$

$17(42.5 \%)$

$6(15 \%)$

$40(100 \%)$ partial to complete airway patency restored. Removal of foreign bodies, mucus plugs, and blood clots was successful in $100 \%$ of cases after the first bronchoscopy.

The median (SD) duration of the procedure was $63 \pm 35$ minutes (range, 11-225 min). Additional therapeutic procedures included mechanical debridement with forceps in 79 patients (51\%), electrocautery in 47 patients (30\%), and APC in 27 patients (17\%). Forceps were used to complement endobronchial recanalization in the segmental and subsegmental airways, and APC and electrocautery were employed to achieve hemostasis and prevent airway obstruction due to clot formation. Balloon dilation was performed either preceding or following $\mathrm{CD}$ in 39 patients (25\%)

(Table 4). CD was the sole method of airway canalization in 42 patients (27\%). The underlying etiology of airway obstruction was malignancy in 16 patients. Thirty-five patients were symptomatic upon presentation. Partial to complete airway patency was achieved in 25 (96\%) of 26 patients with benign airway obstruction and 16 of 16 patients with malignant airway obstruction. Symptom improvement was seen in $29(83 \%)$ of 35 symptomatic patients.

Moderate bleeding in six patients was controlled with iced saline, APC, and electrocautery. There were no cases of pneumothorax or pneumomediastinum. A partial mucosal tear in one patient did not require repair. Respiratory distress requiring ventilatory support with ETI was noted in seven patients, and NIV was used in two patients. All patients recovered. Of the seven patients who required ETI, three were extubated within 24 hours, two were extubated after 3 days, and one remained intubated for 9 days. No procedure-related deaths were reported (Table 5).

Following CD, 89 (62\%) of the 144 symptomatic patients showed substantial improvement, 29 (20\%) experienced either some improvement or remained unchanged, and $18(12 \%)$ worsened. Sixty-five percent of patients who presented with dyspnea as their major symptom showed substantial improvement, and $71 \%$ of patients who presented mainly with hemoptysis improved. Radiologic improvement that manifested as evidence of lung expansion was noted at follow-up in 41 (59\%) of the 70 patients who had CT scans of the chest within 8 weeks of CD.

\section{Discussion}

Lung cancer and other metastatic solidorgan malignancies are the most common causes of symptomatic airway obstruction,
Table 4. Concomitant procedures

\section{Procedure}

Number of Patients ( $[\%]$ )

Stent placement

Balloon dilation

Photodynamic therapy

Mechanical debridement (using forceps)

Argon plasma coagulation

Electrocautery

Other*
$19(12 \%)$

$39(25 \%)$

$9(6 \%)$

$79(51 \%)$

$27(17 \%)$

$47(30 \%)$

$44(28 \%)$
*Endobronchial ultrasound-guided transbronchial needle aspiration, tracheostomy placement or revision, mitomycin $\mathrm{C}$ injection, and fiducial placement. but benign disorders such as strictures, granulation tissue, and benign tumors are also encountered frequently. Thirty percent of patients with lung cancer have involvement of central airways with cough, hemoptysis, dyspnea, and postobstructive pneumonia as potential sequelae $(1,2)$. Symptoms depend on the location, degree, and rapidity of occlusion and can be severe or life threatening, requiring immediate intervention to improve symptoms, oxygenation, and prevent complications $(3-5,8)$.

Bronchoscopic techniques such as neodymium-doped yttrium-aluminumgarnet (Nd:YAG) laser, electrocautery, APC, and mechanical debridement are well established and frequently used to recanalize obstructed airways, often with a multimodality approach. Limitations of these techniques include cost (Nd:YAG laser), risk of airway perforation, and potential risk of airway fire when patients require $\mathrm{FI}_{\mathrm{O}_{2}}$ greater than 0.4 . $\mathrm{CD}$, on the other hand, is a bronchoscopic technique that is inexpensive, has minimal risk of airway perforation, and can be used in high $\mathrm{FI}_{\mathrm{O}_{2}}$ environments, allowing immediate relief of airway obstruction (1).

This study demonstrates that CD is an effective method for palliation of symptoms and airway recanalization and has a good safety profile when used alone or in combination with other endobronchial techniques. In 148 (95\%) of our patients, airway patency was either complete or partial. This finding was very similar for both malignant and benign etiologies. The success rate was comparable to that in a study by Schumann and coworkers (4) and higher than that in a previously reported $83 \%$ success rate (5). Improved patency rates compared with prior studies are likely due to increased experience of interventional bronchoscopists with this technique, as well as to the use of a multimodality approach (4). Although CD can be performed using flexible bronchoscopy with the patient under moderate sedation, in our experience the use of rigid intubation improves the safety of the procedure (1) by providing a secure airway and ventilation while allowing more aggressive debridement and additional interventions such as stent placement (8).

Interestingly, although we were able to achieve partial to complete airway patency 
Table 5. Complication rates according to underlying etiology of airway obstruction

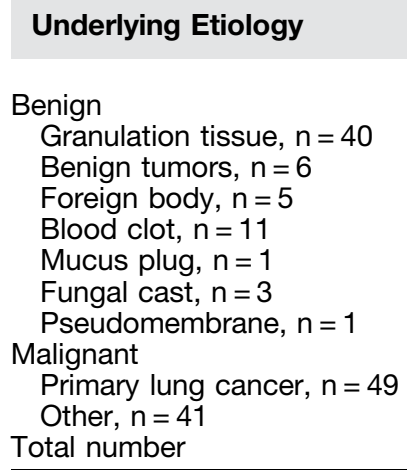

of our patients had significant disease burden and limited lung reserve, putting them at high risk for respiratory compromise after airway manipulation, regardless of the bronchoscopic technique used.

CD can cause airway edema and bronchospasm (1), further increasing the risk of respiratory compromise. Some experts advocate the use of systemic corticosteroids for 24 hours postprocedure, although the benefits of this approach have not yet been proven (1) Finally, in an era when increasing volume of tissue is required for an array of diagnostic tests, including molecular genetic analyses, cryoextraction allows removal of large pieces while preserving the tissue architecture.

Our study has some limitations that are important to discuss. First, airway narrowing was visually estimated at the time of bronchoscopy, which may have led to over- or underestimation of the obstruction. Although it is preferable to calculate the cross-sectional area of the airway lumen, this requires sophisticated software not currently available in our procedural suite. Second, the typical multimodality nature of real-life interventional bronchoscopy makes it difficult in a retrospective analysis to confidently attribute treatment success or complications to a particular technique employed in the course of a procedure. We tried to overcome this limitation by performing a subgroup analysis of cases where CD was either the only or the primary modality used. In the latter, CD was found to be successful in achieving partial to complete airway patency in 41 (98\%) of 42 cases. However, caution should be observed when interpreting these results, given the small number of available cases (42 [27\%] of 156 cases) and the retrospective design of our study. As such, there remains a need for a larger, prospective randomized trial comparing the efficacy and safety of $\mathrm{CD}$ with alternative mechanical or thermal ablation modalities.

In conclusion, $\mathrm{CD}$ is an effective, safe, and inexpensive bronchoscopic tool to achieve immediate airway patency in patients with benign and malignant airway obstruction when performed by experienced operators $(11,15-17)$. It can be used alone or in combination with various other techniques and can be used effectively either with flexible bronchoscopy and conscious sedation or, as in our setting, found in the central airways, which allow better patency rates. In addition, patency is reported, likely due to the concomitant use of electrocautery, APC, and laser (rare) to devitalize highly vascularized tumors such as renal cell carcinoma (12-14). Respiratory failure was seen in 10 patients in this review. This result could be confounded by the fact that the majority 
with general anesthesia and rigid intubation $(8,15,18)$. The cost of setting up cryosurgery, not including the bronchoscope, can be less than $\$ 15,000$, compared with $\$ 200,000$ for an Nd:YAG laser (12, 19), making it an appealing additional tool for most interventional bronchoscopy and thoracic surgical units.
This review of bronchial cryosurgery is one of the largest series published in the English literature; however, the results should be evaluated with caution due to the study's retrospective design reflecting a single center's experience. As such, there remains a need for a prospective, randomized, multicenter study to compare safety, efficacy, and health economic outcomes for the different bronchoscopic interventional modalities commonly used in these settings.

Author disclosures are available with the text of this article at www.atsjournals.org.

\section{References}

1 Sunna R. Cryotherapy and cryodebridement. In: Ernst A, Herth FJF, editors. Principles and practice of interventional pulmonology. New York: Springer Science; 2013. pp. 343-350.

2 Hespanhol V, Magalhães A, Marques A. Neoplastic severe central airways obstruction, interventional bronchoscopy: a decisionmaking analysis. J Thorac Cardiovasc Surg 2013;145:926-932.

3 Maiwand MO, Asimakopoulos G. Cryosurgery for lung cancer: clinical results and technical aspects. Technol Cancer Res Treat 2004;3: 143-150.

4 Schumann C, Hetzel M, Babiak AJ, Hetzel J, Merk T, Wibmer T, Lepper PM, Krüger S. Endobronchial tumor debulking with a flexible cryoprobe for immediate treatment of malignant stenosis. $J$ Thorac Cardiovasc Surg 2010;139:997-1000.

5 Hetzel M, Hetzel J, Schumann C, Marx N, Babiak A. Cryorecanalization: a new approach for the immediate management of acute airway obstruction. J Thorac Cardiovasc Surg 2004;127:1427-1431.

6 Sriratanaviriyakul N, Lam F, Morrissey BM, Stollenwerk N, Schivo M, Yoneda KY. Safety and clinical utility of flexible bronchoscopic cryoextraction in patients with non-neoplasm tracheobronchial obstruction: a retrospective chart review. J Bronchology Interv Pulmonol 2015;22:288-293.

7 Kuo SC, Lo YL, Chou CL, Chung FT, Lin SM, Liu CY, Kuo HP. Bronchoscopic debulking for endobronchial malignancy: predictors of recanalization and recurrence. Thorac Cancer 2015;6:722-730.

8 Jeon K, Kim H, Yu CM, Koh WJ, Suh GY, Chung MP, Kwon OJ. Rigid bronchoscopic intervention in patients with respiratory failure caused by malignant central airway obstruction. $J$ Thorac Oncol 2006;1: 319-323.

9 Sachdeva A, Pickering EM, Lee HJ. From electrocautery, balloon dilatation, neodymium-doped:yttrium-aluminum-garnet (Nd:YAG) laser to argon plasma coagulation and cryotherapy. $J$ Thorac Dis 2015;7(Suppl 4):S363-S379.

10 Mazur $P$. The role of intracellular freezing in the death of cells cooled at supraoptimal rates. Cryobiology 1977;14:251-272.

11 Vergnon JM, Huber RM, Moghissi K. Place of cryotherapy, brachytherapy and photodynamic therapy in therapeutic bronchoscopy of lung cancers. Eur Respir J 2006;28:200-218.

12 Marasso A, Gallo E, Massaglia GM, Onoscuri M, Bernardi V. Cryosurgery in bronchoscopic treatment of tracheobronchial stenosis. Indications, limits, personal experience. Chest 1993;103: 472-474.

13 Bolliger CT, Sutedja TG, Strausz J, Freitag L. Therapeutic bronchoscopy with immediate effect: laser, electrocautery, argon plasma coagulation and stents. Eur Respir J 2006;27: 1258-1271.

14 Wahidi MM, Unroe MA, Adlakha N, Beyea M, Shofer SL. The use of electrocautery as the primary ablation modality for malignant and benign airway obstruction. $J$ Thorac Oncol 2011;6:1516-1520.

15 Ernst A, Feller-Kopman D, Becker HD, Mehta AC. Central airway obstruction. Am J Respir Crit Care Med 2004;169:1278-1297.

16 Yarmus L, Ernst A, Feller-Kopman D. Emerging technologies for the thorax: indications, management and complications. Respirology 2010;15:208-219.

17 Majid A, Palkar A, Myers R, Berger RL, Folch E. Cryotechnology for staged removal of self-expandable metallic airway stents. Ann Thorac Surg 2013;96:336-338.

18 Mathur PN, Wolf KM, Busk MF, Briete WM, Datzman M. Fiberoptic bronchoscopic cryotherapy in the management of tracheobronchial obstruction. Chest 1996;110:718-723.

19 Coulter TD, Mehta AC. The heat is on: impact of endobronchial electrosurgery on the need for $\mathrm{Nd}-\mathrm{YAG}$ laser photoresection. Chest 2000;118:516-521. 